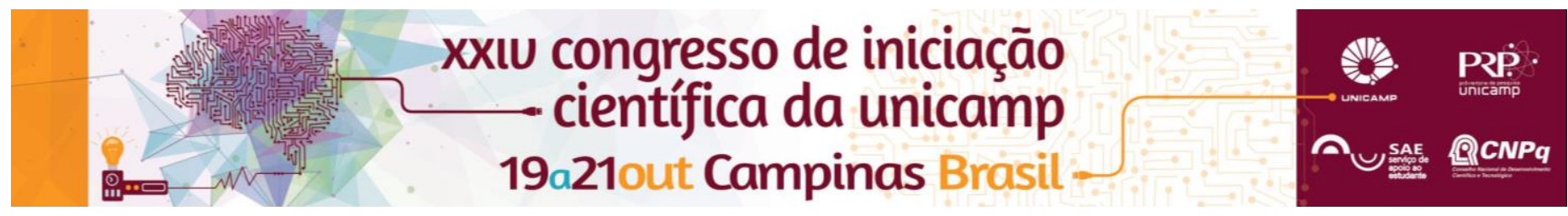

\title{
Efeito de enxaguatórios contendo peróxido de hidrogênio associado a pirofosfatos na morfologia superficial do esmalte e suscetibilidade ao manchamento.
}

\author{
Vitória Massoneto Piccoli*, Waldemir F. Vieira-Junior, Jéssica D. Theobaldo, Débora Alves Nunes Leite Lima, \\ Flavio Henrique Baggio Aguiar.
}

\section{Resumo}

Os efeitos de produtos OTC ("over-the-counter") contendo peróxido de hidrogênio (PH) sobre os tecidos dentais não são totalmente conhecidos. Esse estudo avaliou o efeito do uso de enxaguatórios contendo $\mathrm{PH}$ associado ou não a pirofosfatos $(\mathrm{Pi})$ em um modelo de manchamento com café, em relação à morfologia superficial do esmalte, efetividade e estabilidade clareadora. Nenhum enxaguatório promoveu alteração de cor clinicamente perceptível, entretanto o enxaguatório contendo somente $\mathrm{PH}$ causou alteração da morfologia superficial. Os enxaguatórios alteraram a suscetibilidade ao manchamento, sendo que o enxaguatório contendo somente $\mathrm{PH}$ aumentou e a adição de $\mathrm{Pi}$ diminuiu esta suscetibilidade.

Palavras-chave:

clareamento, peróxido de hidrogênio,cor

\section{Introdução}

Produtos OTC ("over-the-counter") são aqueles vendidos, com objetivos clareadores, diretamente ao paciente e encontrados em farmácias ou supermercados, como os enxaguatórios com peróxido de hidrogênio $(\mathrm{PH})$. O objetivo deste estudo in vitro foi avaliar os efeitos morfológicos e cromáticos no esmalte submetido ao tratamento com enxaguatórios contendo $\mathrm{PH}$, associados ou não a pirofosfatos $(\mathrm{Pi})$, exposto a um modelo de manchamento diário.

\section{Resultados e Discussão}

Métodos: 72 blocos de esmalte/dentina bovinos foram aleatoriamente divididos $(n=12)$ em protocolos de tratamento diário por 21 dias $(2 \times$ ao dia): A) G1 e G4 água destilada (controle); B) G2 e G5 - Colgate Plax Whitening ${ }^{\circledR} \quad\left(\mathrm{H}_{2} \mathrm{O}_{2}, 1,5 \%\right) ;$ e C) G3 e $\mathrm{G} 6$ - Colgate Luminous White $\AA\left(\mathrm{H}_{2} \mathrm{O}_{2} 2 \%+\right.$ Pirofosfatos). Os grupos foram expostos (G4, G5 e G6) ou não (G1, G2 e G3) a um ciclo de manchamento diário com café (10 min) por 21 dias (T1) e todos os grupos foram submetidos a 7 dias de manchamento após o uso dos enxaguatórios (T2). Durante todo o experimento, as amostras foram armazenadas em saliva artificial. A morfologia do esmalte foi verificada pela análise da variação de rugosidade $(\triangle \mathrm{Ra})$ e microscopia eletrônica de varredura (MEV) e a avaliação da cor por espectrofotometria de reflectância (CIE L*a*b* - $\Delta E, \Delta \mathrm{L}, \Delta \mathrm{a}$ e $\Delta \mathrm{b}$ ). Os dados foram submetidos à análise de variância (ANOVA) e teste de Tukey $(\alpha=0,05)$. Resultados: $O$ enxaguatório contendo $\mathrm{H}_{2} \mathrm{O}_{2} \quad 1,5 \%$ promoveu alteração da $\mathrm{Ra}$ do esmalte, independente da presença do manchamento $(p<0,01)$. $O$ esmalte exposto ao enxaguatório contendo $\mathrm{H}_{2} \mathrm{O}_{2} 2 \%+\mathrm{Pi}$ não sofreu alteração de rugosidade (Inicial X T1), não diferindo do grupo sem tratamento. Na análise de cor, a exposição do esmalte não manchado ao enxaguatório contendo $\mathrm{H}_{2} \mathrm{O}_{2} 1,5 \%$ promoveu variação positiva da coordenada $\mathrm{L}^{*}$, promovendo alteração de cor clinicamente não perceptível $(\Delta E=2,91)$, diferindo estatisticamente do controle sem tratamento $(p<0,05)$. $O$ enxaguatório contendo $\mathrm{H}_{2} \mathrm{O}_{2} 2 \%+\mathrm{Pi}$ não foi efetivo em promover $\Delta \mathrm{L}$ positiva em $\mathrm{T} 1$, porém nos grupos manchados (T1 e T2) o tratamento do esmalte com o enxaguatório contendo $\mathrm{H}_{2} \mathrm{O}_{2} 2 \%+\mathrm{Pi}$ apresentou $\Delta \mathrm{E}$ e $\Delta \mathrm{L}$ menores e estatisticamente diferentes do controle sem DOI: 10.19146/pibic-2016-51104 tratamento $(p<0.01)$. Na comparação T1xT2, o esmalte não manchado e exposto ao enxaguatório Plax Whitening ${ }^{\circledR}$ em T1, apresentou a maior variação negativa de $L^{*}$, positiva de $b^{*}$ e maiores valores de $\Delta E$ $(p<0,05)$, demonstrando potencialização do manchamento. MEV: A exposição ao enxaguatório com $\mathrm{H}_{2} \mathrm{O}_{2} \quad 1,5 \%$ promoveu alteração de morfologia do esmalte, com dissolução mineral interprismática.

O peróxido de hidrogênio possui um efeito oxidativo não específico e possui ação também sobre a composição mineral do esmalte causando alterações como o aumento da permeabilidade e da rugosidade superficial (Camargo et al., 2007; Markovic et al., 2007), fatores associados a pigmentação do substrato. Em contrapartida, os pirofosfatos são agentes que possuem alta afinidade com hidroxiapatita $(\mathrm{HA})$ e interagem com 0 cálcio da estrutura. Ao interagir com o HA e a superfície do esmalte, os pirofosfatos reduzem a capacidade de ligação de proteínas ou cromógenos (Segreto et al., 1998).

O enxaguatório contendo somente peróxido de hidrogênio 1,5\% (Colgate Plax Whitening®) não demonstrou efeito clareador significativo, alterando negativamente a morfologia superficial do esmalte $e$ aumentando a suscetibilidade ao manchamento. Entretanto, o enxaguatório com adição de pirofosfatos não promoveu alteração de morfologia do esmalte e foi efetivo na diminuição do manchamento.

\section{Agradecimentos}

Ao Pibic-Unicamp pela concessão da bolsa de iniciação científica.

Camargo SEA, Valera MC, Camargo CHR, Mancini MNG and Menezes MM (2007) Penetration of $38 \%$ hydrogen peroxide into the pulp chamber in bovine and human teeth submitted to office bleach technique Journal of Endodontics 33(9) 1074-1077.

Markovic L, Jordan RA, Lakota N, and Gaengler P (2007) Micromorphology of enamel surface after vital tooth bleaching Journal of Endodontics 33(5) $607-610$.

Segreto VA, Stevens DP, Schulte MC, Fortna RH, Gerlach RW. Safety and efficacy of novel tartar control dentifrice containing $3.3 \%$ phyrophosphate: a controlled six-month clinical trial J Clin Dent 1998;9:t26-29. 